\title{
Upregulation of E2F transcription factor 3 is associated with poor prognosis in hepatocellular carcinoma
}

\author{
XIAOYUN ZENG ${ }^{1,2 *}$, FUQIANG YIN ${ }^{1 *}$, XIA LIU $^{3}$, JIANWEN XU ${ }^{4}$, YANG XU $^{2}$, \\ JINMEI HUANG ${ }^{5}$, YUELI NAN ${ }^{2}$ and XIAOQIANG QIU ${ }^{2}$ \\ ${ }^{1}$ Medical Scientific Research Centre; ${ }^{2}$ Department of Epidemiology and Health Statistics, School of Public Health; \\ ${ }^{3}$ Centre for Translational Medicine, Guangxi Medical University; ${ }^{4}$ The First Affiliated Hospital of \\ Guangxi University of Chinese Medicine; ${ }^{5}$ Guangxi Zhuang Autonomous Region Centre \\ for Disease Prevention and Control, Nanning, Guangxi 530021, P.R. China
}

Received October 16, 2013; Accepted November 18, 2013

DOI: $10.3892 /$ or.2014.2968

\begin{abstract}
E2F transcription factor 3 (E2F3), a member of the E2F transcription factor family and a member of the genes involved in the regulation of cell cycle, is an oncogene with strong proliferative potential. E2F3 is involved in many processes and plays important roles in the development of several types of cancer, while its relationship with prognosis in hepatocellular carcinoma (HCC) has yet to be reported. In the present study, based on 4 independent microarray data sets which covered 385 cases of HCC and 327 cases of normal livers retrieved from the Oncomine database, we demonstrated that E2F3 was upregulated at least 1.5-fold and on average 2.3-fold in $\mathrm{HCC}$ when compared with normal controls. Comprehensive bioinformatics analysis consisting of protein-protein interaction, gene co-occurrence, microRNA-mRNA interaction and biological process annotation indicated that E2F3 interacted with a large number of genes, proteins and microRNAs which were all associated with poor prognosis in patients with HCC and other types of cancer, suggesting that E2F3 may also serve as a biomarker for poor prognosis. Taken together, for the first time, we show that the overexpression of E2F3 may be associated with unfavorable prognosis in HCC.
\end{abstract}

\section{Introduction}

Hepatocellular carcinoma (HCC) is the third leading cause of cancer-related mortality worldwide, owing to a very high

Correspondence to: Professor Xiaoqiang Qiu, Department of Epidemiology and Health Statistics, School of Public Health, Guangxi Medical University, 22 Shuangyong Road, Nanning, Guangxi 530021, P.R. China

E-mail: xqqiu9999@sina.com

\section{${ }^{*}$ Contributed equally}

Key words: E2F transcription factor 3, prognosis, hepatocellular carcinoma, bioinformatics mortality to incidence ratio of 0.93 (1). Surgery, including liver transplantation, remains the only curative modality for HCC. However, despite resection with curative intent, the clinical course is variable and the long term prognosis is poor with reported 5-year survival rates ranging from 17 to $53 \%$ (2). There is an ongoing search for predictive biomarkers of cancer prognosis, where, among others, protein biomarkers, mRNA expression level, pathological parameters, clinicopathologic parameters and genomic DNA abnormalities are surveyed (3-5). Among all the biomarkers of HCC prognosis, mRNA expression level of some genes is associated with prognosis of patients with HCC, including tumor-suppressor and promoter genes, genes involved in growth inhibition and apoptosis, genes regulating DNA damage, cell cycle regulators, genes responding to the cell invasion and metastasis, genes responsible for cell-cell interaction (2). Among other things, a large number of genes regulating cell cycle have been proven to be associated with prognosis in HCC patients. For instance, overexpression of cyclin A, D1, and $\mathrm{E}$ has been found to correlate with the relapse of HCC and are independent predictive markers for recurrence and prognosis $(6,7)$. In addition, Singhal et al (2) reported that p15, p16, p18, p19, p21, p27 and p57, which were all potent negative cell cycle regulators inhibiting the G1/S transition, are associated with prognosis in patients with HCC.

E2F is a family of transcription factors that, in coordination with DP and pocket proteins [retinoblastoma protein (pRB), p107, p130], regulates the G1/S-phase transition of cell cycle (8) and its activity is regulated by the pRB, a tumorsuppressor that is functionally inactivated in most human tumors (9-11). E2F transcription factors have been proven to be associated with prognosis in cancer. For example, high expression of E2F1 and E2F2 was associated with poor prognosis in breast cancer $(12,13)$, and the expression of E2F4 is associated with poor prognosis in $\mathrm{HCC}$ (14). Although E2F transcription factor 3 (E2F3), a member of E2F transcription factors, plays important roles in the development of HCC and other types of cancer, its role in prognosis in patients with $\mathrm{HCC}$ and other types of cancer has not been reported. In the present study, on the basis of comprehensive bioinformatics analyses, we illustrated that the overexpression of E2F3 may be a biomarker for prognosis in patients with $\mathrm{HCC}$. 


\section{Materials and methods}

The target gene, E2F3, which is a member of the genes involved in the regulation of cell cycle (KEGG map 04110) according to the Kyoto Encyclopedia of Genes and Genomes (KEGG) pathway maps (http://www.genome.jp/kegg/pathway. html) (15) was selected for bioinformatics analysis.

The microarray data of E2F3 were retrieved from the Oncomine online database (https://www.oncomine.org/resource/ main.html) (16); the protein-protein interaction network was generated using GeneMANIA online tool (http://www.genemania.org/) (17); the microRNAs (miRNAs) targeted to the gene were predicted by miRWalk online tool which included 9 prediction tools such as TargetScan (http://www.umm.uni-heidelberg. de/apps/zmf/mirwalk/) (18); annotation of biological processes and gene co-occurrence were performed using the Coremine online tool (http://www.coremine.com/medical/) (19).

\section{Results}

Functions of E2F3 in cancer. E2F3 can specifically bind to pRB in a cell cycle-dependent manner and has a central role in linking cell cycle proteins, such as cyclin-dependent kinases (CDKs), cyclins and pRB, to the expression of a variety of genes involved in cell cycle progression and cellular proliferation $(9,11)$. In addition, as an oncogene with strong proliferative potential, E2F3 modulates different genes that play a crucial role in DNA synthesis, transcription and signal transduction, and it is regularly dysregulated or overexpressed in cancer (20). It has been proven that E2F3 is involved in many processes during cancer development, such as cell proliferation, DNA damage, apoptosis and drug resistance. Using both in vitro and in vivo approaches, Martinez et al (21) demonstrated that E2F3 functions as a master regulator of the DNA damage response and is required for DNA damage-induced apoptosis. Amplification and overexpression of the E2F3 gene in human bladder cancer is associated with increased tumor stage, grade and proliferation index and, in prostate cancer, E2F3 overexpression is linked to tumor aggressiveness. For both bladder and prostate cancer, overexpression of the $\mathrm{E} 2 \mathrm{~F} 3$ protein may cooperate with removal of the E2F inhibitor tumor-suppressor pRB to drive cellular proliferation. Thus, E2F3 is considered to have a critical role in modifying cellular proliferation rate in human bladder and prostate cancer (22). In addition, downregulation of miR-200b may lead to E2F3 overexpression and in turn contribute to decreasing the sensitivity of lung adenocarcinoma cells to docetaxel (23).

Studies on E2F3 with HCC are limited. Only few studies indicated that E2F3 may play important roles in the development of liver cancer. miR-195 can block the $\mathrm{G}_{1} / \mathrm{S}$ transition by suppressing $\mathrm{Rb}-\mathrm{E} 2 \mathrm{~F}$ signaling through targeting multiple molecules including E2F3, suggesting that E2F3 plays important roles in cell cycle control and in the molecular etiology of HCC (24). The inhibition of expression of miRNAs miR-34a, miR-127, miR-200b and miR-16a is involved in the regulation of apoptosis, cell proliferation, cell-to-cell connection and epithelial-mesenchymal transition, while the mechanistic link between these alterations in miRNA expression and the development of $\mathrm{HCC}$ was mediated by the corresponding changes in the levels of E2F3, NOTCH1, BCL6, ZFHX1B and BCL2

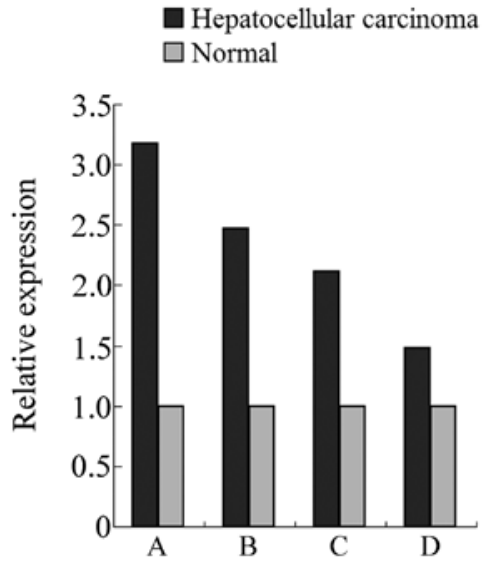

Figure 1. The relative expression of E2F3 in hepatocellular carcinoma and normal livers based on the microarray data retrieved from the Oncomine online database. (A) Wurmbach liver statistics which cover 35 cases of hepatocellular carcinoma and 10 normal controls $(\mathrm{P}=2.32 \mathrm{e}-6)$. (B) Roessler liver statistics which cover 22 cases of hepatocellular carcinoma and 21 normal controls $(\mathrm{P}=3.93 \mathrm{e}-7)$. (C) The Roessler liver 2 statistics which cover 225 cases of hepatocellular carcinomas and 220 normal controls $(\mathrm{P}=6.67 \mathrm{e}-52)$. (D) The Chen liver statistics which cover 103 cases of hepatocellular carcinomas and 76 normal controls $(\mathrm{P}=1.79 \mathrm{e}-7)$. These data in the Oncomine database were presented as fold changes (hepatocellular carcinoma vs. normal). In the present study, the expressions of E2F3 in normal control were normalized to 1.0 and the data are presented as relative expression. E2F3, E2F transcription factor 3.

proteins targeted by these miRNAs. These results indicate that E2F3 may be associated with apoptosis, cell proliferation, cell-to-cell connection and epithelial-mesenchymal transition in $\mathrm{HCC}(25)$.

$\mathrm{E} 2 \mathrm{~F} 3$ is involved in many processes and plays key roles in cancer, while its relationship with HCC is limited and its associations with prognosis in cancer are rare, with only one study indicating that E2F3 may be an independent factor predicting overall survival and cause-specific survival in prostate cancer (26). Thus, in the present study, based on the comprehensive bioinformatics analysis, we elucidated that the overexpression of E2F3 may be associated with prognosis in patients with HCC.

E2F3 is overexpressed in HCC. The relative expression of E2F3 in HCC and normal livers was analyzed based on the array data retrieved from the Oncomine online database. As shown in Fig. 1, on the basis of 4 independent microarray data sets which covered 385 cases of HCC and 327 cases of normal livers, we revealed that $\mathrm{E} 2 \mathrm{~F} 3$ was upregulated in $\mathrm{HCC}$ when compared with normal controls, with at least 1.5 -fold and on average 2.3-fold changes. This result indicated that E2F3, an oncogene, may play significant roles in the development of HCC and its overexpression in tumors may be associated with prognosis.

E2F3 interacts with tens of proteins associated with poor prognosis in HCC. Protein-protein interactions of E2F3 with other proteins were analyzed using GeneMANIA online tool. As shown in Fig. 2, E2F3 had direct interactions with a total of 16 proteins and, among them, E2F3 co-expressed with FOXC1, KL, NFYA, KIF14, FOXM1, WHSC1 and NCAPH, co-expressed and co-localized with BUB1B and DKC1, co-localized with PLK4, SPAG5, CCNA2 and RUNX1, co-expressed and shared protein domains with E2F1 and E2F2 


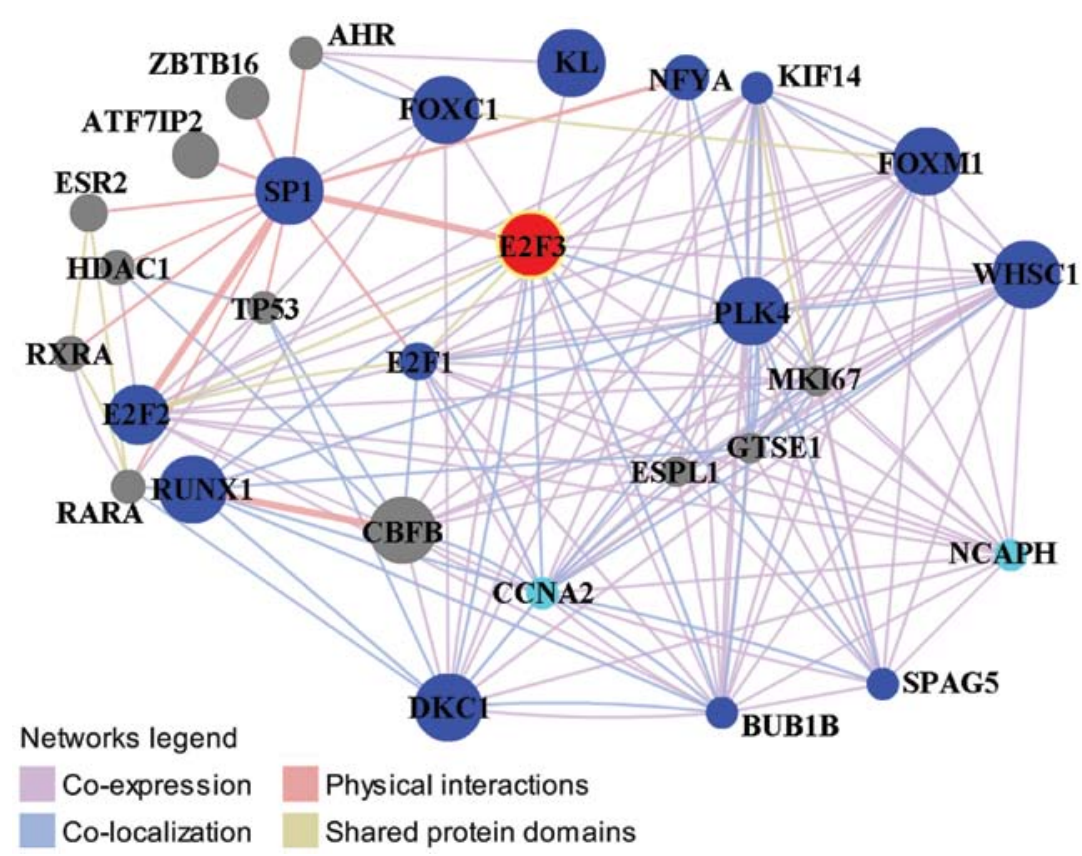

Figure 2. The protein-protein interaction network of E2F3 generated using GeneMANIA online tool. A total of 16 proteins had direct interactions with E2F3 and, among them, 14 (the query in dark blue) were associated with prognosis in HCC and other types of cancer. The association with prognosis in cancer of only 2 proteins (the query in light blue) remains to be identified. E2F3, E2F transcription factor 3; HCC, hepatocellular carcinoma.

and had strong physical interactions with SP1. With the exception of the NCAPH and CCNA2, these proteins/genes are associated with prognosis in patients with HCC and other types of cancer. It has been proven that high expression of FOXC1 is associated with poor prognosis in several types of solid tumors including non-small cell lung cancer (27), pancreatic ductal adenocarcinoma (28) and basal-like breast cancer (29). In HCC, patients with positive FOXC1 expression have shorter overall survival times and higher recurrence rates than those with negative FOXC1 expression, indicating that high expression of FOXC1 is an independent, significant risk factor for recurrence and survival (30). Klotho gene (KL) is identified as a tumor-suppressor in several tumors, and its downregulation is closely associated with poor prognosis in several types of tumors such as gastric (31) and breast cancer (32). In HCC, a significant loss of KL mRNA and protein expression was observed in tumors, which parallels the increased methylation in KL promoter DNA, and both KL expression and methylation correlated with the poor prognosis of HCC (33). KIF14 mRNA and protein expression are respectively increased 5.5- and 4.2-fold on average in glioma tissues when compared to non-neoplastic brain tissues. Furthermore, both univariate and multivariate Cox regression analyses determined that KIF14 overexpression effectively predicted decreased overall survival in patients with gliomas (34). In HCC, the expression of KIF14 is significantly increased and has significant associations with an unfavorable prognosis (35). Overexpression of FOXM1 can greatly increase the death hazard [hazard ratio, 1.899; 95\% confidence interval (CI), 1.016-3.551] and thus closely associates with poor prognosis of non-small cell lung cancer patients through promoting tumor metastasis (36). Similarly, FOXM1 expression is significantly associated with cisplatin-based chemotherapy resistance and poor prognosis in advanced non-small cell lung cancer patients (37). In
HCC, overexpression of FOXM1, which is regulated by the TNF- $\alpha$ /reactive oxygen species/HIF-1 pathway (38), is associated with aggressive tumor features and poor prognosis of patients (39). WHSC1 is also a poor prognostic factor in cancer. A combined use of microarray technologies and bioinformatics analyses revealed that a critical-gene model, comprising FAM53B, KIF21B, WHSC1 and TMPO, predicted survival in all data sets with follow-up information in multiple myeloma, indicating that WHSC1 is a significant prognostic factor (40). Regarding BUB1B, unsupervised clustering analysis strongly discriminated the malignant tumors, suggesting that the combined expression of BUB1B and PINK1 is the best predictor of overall survival $\left(\mathrm{P}<2 \times 10^{-6}\right)(41)$. DKC1 is an essential nucleolar protein involved in cell proliferation. DKC1 was shown to be overexpressed in paraffin sections of 252 HCC cases when compared with 80 non-cancerous liver tissues at the protein level and was overexpressed in $80 \mathrm{HCC}$ and 50 non-cancerous tissues at the transcript level and the multivariate analysis suggested that overexpression of DKC1 is an independent unfavorable prognosis factor (hazard risk, 2.912; $\mathrm{P}=0.007$ ) in HCC (42). Polo-like kinase 4 (PLK4), belonging to the serine/threonine kinase family, is critical for centriole replication and cell cycle progression and has been proposed as a tumor-suppressor in HCC. Decreased expression of PLK4 is present in $72.4 \%$ (178/246) of HCC tissues and HCC patients with low PLK4 expression have shorter survival than those with high PLK4 expression (43). Patients with low E2F1-expressing tumors are associated with favorable outcome (hazard ratio $=4.3 ; 95 \% \mathrm{CI}=1.8-9.9 ; \mathrm{P}=0.001$ ) in breast cancer (12), indicating that high expression of E2F1 is associated with poor prognosis. In addition, high expression of RUNX1 and SPAG5 are associated with poor prognosis in acute myeloid leukemia (44), and estrogen receptor positive breast cancer (45), respectively. 


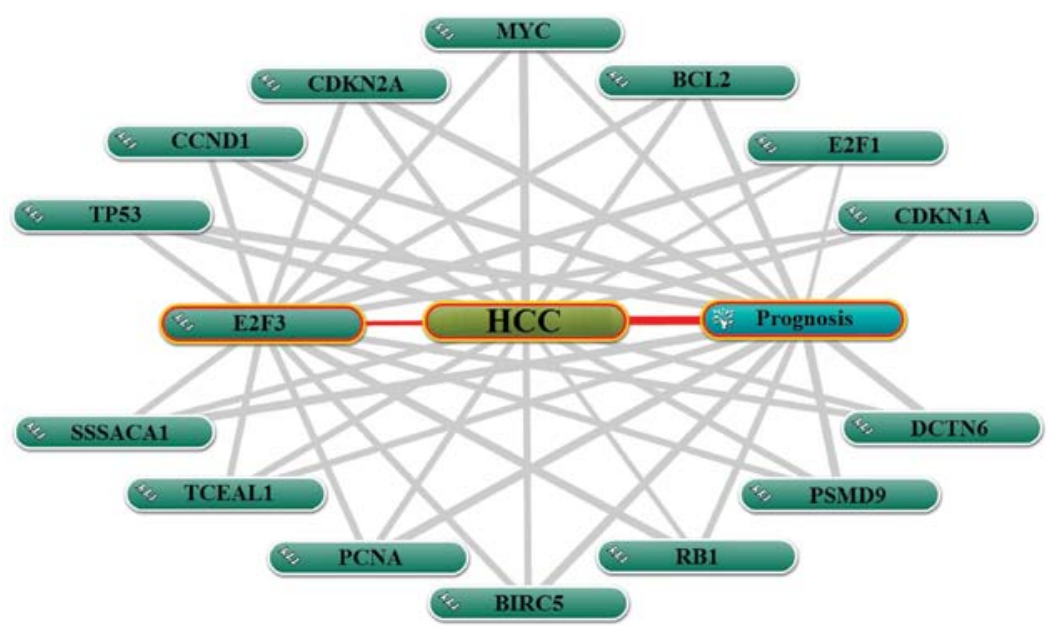

Figure 3. The co-occurred genes of E2F3 with $\mathrm{HCC}$ and prognosis generated by the Coremine online tool. The top 14 genes which co-occurred with the three terms at most times were included $(\mathrm{P}<0.00209)$. E2F3, E2F transcription factor 3; HCC, hepatocellular carcinoma.

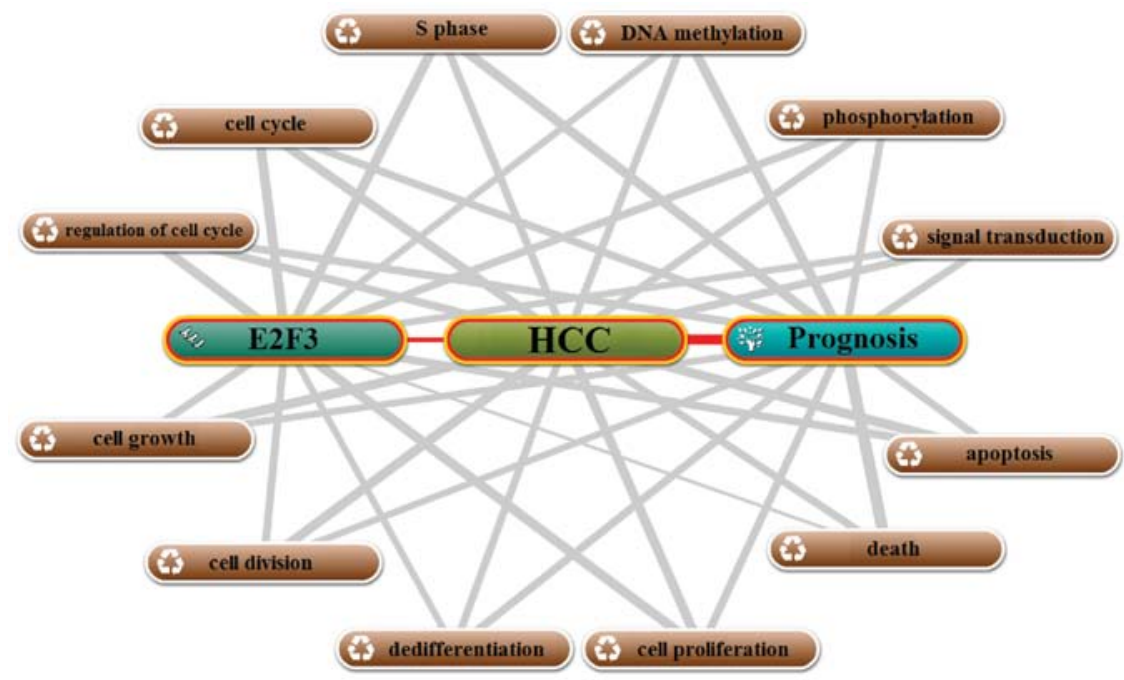

Figure 4. Annotation of biological processes of E2F3 with $\mathrm{HCC}$ and prognosis using the Coremine online database. The top 12 biological processes which closely related to the three terms were annotated $(\mathrm{P}<0.00209)$. E2F3, E2F transcription factor 3; HCC, hepatocellular carcinoma.

Nuclear factor YA (NFYA), E2F2 and SP1 are known to be associated with unfavorable prognosis indirectly in cancer. For example, high ALDH expression is associated with poor prognosis in uterine endometrial adenocarcinoma, while the ALDH activity is transcriptionally regulated by ALDH1A1 for which the promoter region contained CCAAT and octamer binding motifs. Among CCAAT-recognizing transcription factors, NFYA is involved in ALDH1A1 transcription (46). This result suggests that NFYA responds to poor prognosis via ALDH1A1 and ALDH in uterine endometrial adenocarcinoma. Overexpression of the human epidermal growth factor receptor 2 (HER2) in breast tumors is associated with poor prognosis, and the high expression of E2F2, CCND1 and CCND3 can increase the levels of factors upregulating HER2 (13). Regarding the relationship of SP1 with cancer, a study revealed that the promoter hypomethylation upregulates CD147 expression primarily through increasing SP1 binding and is associated with poor prognosis in HCC patients (47). Similarly, SP1 binding site is important for mediating CADM1 promoter activity which is associated with poor prognosis in
HCC (48). These results indicate that SP1 is closely related to poor prognosis in HCC patients through mediating certain genes.

Among a total of 16 proteins/genes which had direct interactions with E2F3, 14 of them were associated with poor prognosis in several types of cancer, and among those 14 proteins/genes, 8 were associated with poor prognosis in patients with HCC. These results strongly indicate that E2F3 may be associated with poor prognosis in patients with HCC.

Function prediction and analysis based on the co-occurred genes. As shown in Fig. 3, E2F3 co-occurred with a total of 14 genes, suggesting that they have a close relationship with each other. The 14 genes co-occurred with HCC and prognosis, indicating that they were closely related to $\mathrm{HCC}$ development and prognosis in cancer. Among the 14 genes, 8 of them, MYC (42), CDKN2A (49), CCND1 (50), TP53 (51,52), Bcl2 and PCNA (52), RB1 (53) and E2F1 (54), have been proven to be involved in prognosis for patients with HCC. Furthermore, among the 14 genes, E2F1 and TP53 also appeared in the 
Table I. The top 10 miRNAs targeted to E2F3 associated with unfavorable prognosis in patients with HCC and other types of cancer.

\begin{tabular}{|c|c|c|c|c|c|c|c|c|c|c|}
\hline \multirow{2}{*}{$\begin{array}{l}\text { miRNA } \\
\text { (Hsa-) }\end{array}$} & \multicolumn{9}{|c|}{ miRNA-mRNA interaction tool } & \multirow{2}{*}{$\begin{array}{c}\text { The miRNA is associated with } \\
\text { poor prognosis in cancer }\end{array}$} \\
\hline & a & $\mathrm{b}$ & $\mathrm{c}$ & $\mathrm{d}$ & $\mathrm{e}$ & $\mathrm{f}$ & $\mathrm{g}$ & $\mathrm{h}$ & $\mathrm{i}$ & \\
\hline $\operatorname{miR}-15 b$ & 1 & 1 & 0 & 1 & 1 & 1 & 1 & 1 & 1 & $\mathrm{HCC}(55)$ \\
\hline $\operatorname{miR}-34 a$ & 1 & 1 & 0 & 1 & 1 & 1 & 1 & 1 & 1 & Resectable pancreatic ductal adenocarcinoma (60) \\
\hline $\operatorname{miR}-15 \mathrm{a}$ & 1 & 1 & 0 & 1 & 1 & 1 & 1 & 1 & 1 & $\mathrm{HCC}(55)$ \\
\hline miR-200c & 1 & 1 & 1 & 1 & 1 & 0 & 1 & 1 & 1 & Pancreatic cancer (65) \\
\hline miR-141 & 1 & 1 & 1 & 1 & 1 & 0 & 1 & 1 & 1 & Colon cancer (56), lung cancer (57) \\
\hline $\operatorname{miR}-200 b$ & 1 & 1 & 1 & 1 & 1 & 0 & 1 & 1 & 1 & Ovarian cancer (61), lung cancer (23) \\
\hline $\operatorname{miR}-152$ & 1 & 1 & 0 & 1 & 1 & 1 & 1 & 1 & 1 & Endometrial serous adenocarcinomas (62) \\
\hline $\operatorname{miR}-195$ & 1 & 1 & 0 & 1 & 1 & 1 & 1 & 0 & 1 & Colorectal cancer (63), gastric cancer (59) \\
\hline $\operatorname{miR}-30 b$ & 1 & 1 & 0 & 1 & 1 & 0 & 1 & 1 & 1 & $\mathrm{HCC}(55)$ \\
\hline miR-103 & 1 & 1 & 0 & 1 & 1 & 1 & 1 & 1 & 0 & Colorectal cancer $(58)$ \\
\hline
\end{tabular}

a, DIANAmT; b, miRanda; c, miRDB; d, miRWalk; e, RNAhybrid; f, PICTAR4; g, PICTAR5; h, PITA; i, targetscan; 1, predicted; 0, not predicted. miRNAs, microRNAs; E2F3, E2F transcription factor 3; HCC, hepatocellular carcinoma.

protein interaction network of E2F3 (Fig. 2). Therefore, we concluded that E2F3 co-occurred with 14 genes which were all associated with prognosis in HCC and other types of cancer and may be associated with prognosis in patients with HCC.

Function prediction and analysis based on the annotated biological processes. The annotation of biological processes of E2F3 with HCC and prognosis were generated with the Coremine online tool. As shown in Fig. 4, a total of 12 biological processes were closely associated with E2F3, HCC and prognosis at the same time, suggesting that E2F3 may be involved in the prognosis of HCC patients through these processes. Among the 12 processes, 3 , including $\mathrm{S}$ phase, cell cycle and regulation of cell cycle, were cell cycle-related, and 6 , including cell growth, cell division, dedifferentiation, cell proliferation, death and apoptosis were 'growth/death'-related. Previous studies proved that E2F3 contributes to promote the $\mathrm{G}_{1} / \mathrm{S}$-phase transition of cell cycle and has a central role in linking cell cycle proteins to the expression of a variety of genes involved in cell cycle progression and cellular proliferation $(9,11)$. Furthermore, E2F3, an oncogene with strong proliferative potential (20), plays important roles in cell proliferation, DNA damage and apoptosis $(21,22)$. Thus, we conclude that E2F3 may be associated with prognosis in HCC mainly through cell cycle, 'growth/death'-related biological processes.

The miRNA-mRNA interaction indicating E2F3 is related to poor prognosis in HCC patients. As shown in Table I, the top 10 miRNAs targeted to E2F3 were predicted by 9 prediction tools and the relationship of these miRNAs with prognosis in cancer was reviewed and integrated. The top 10 miRNAs are associated with prognosis in several types of cancer. For example, high expression levels of miR-15b and miR-30b are significantly associated with a shorter recurrence-free survival in HCC (55), high levels of miR-141 in plasma are associated with poor prognosis in patients with colon (56) and lung cancer (57), high expression of miR-103 is associated with poor prognosis in patients with colorectal cancer (58) and high expression of miR-195 is associated with poorer prognosis for both recurrence and survival in gastric cancer (59). In addition, downregulation of miR-34a is independently associated with reduced survival in patients with resectable pancreatic ductal adenocarcinoma (60), decreased miR-200b expression is correlated with poor prognosis in patients with ovarian (61) and lung cancer (23), lower expression of miR-152 is significantly correlated with poor overall survival and poor disease-free survival in endometrial serous adenocarcinomas (62) and downregulation of miR-195 correlates with poor prognosis in colorectal cancer (63). In addition, miR-200c is downregulated in HCC tissues (64) and in pancreatic cancer patients (65) and its downregulation has significantly poorer survival rates in the pancreatic cancer (65). One exception is that high expression levels of miR-15a were significantly associated with a longer recurrence-free survival in HCC (55), but this may reversely indicate that lower expression of miR-15 may be associated with a shorter recurrence-free survival. Thus, among the top 10 miRNAs targeted to E2F3, all are associated with poor prognosis in cancer and 3 of them are associated with shorter survival in $\mathrm{HCC}$, indicating that $\mathrm{E} 2 \mathrm{~F} 3$ may be associated with poor prognosis in $\mathrm{HCC}$ and other types of cancer.

\section{Discussion}

HCC is a fatal liver malignancy with an exceptionally high incidence in Asia and Africa. The number of new cases in America and Europe is rapidly increasing, making $\mathrm{HCC}$ a worldwide health problem (66). Although the mortality of HCC has significantly decreased with the development of surgical techniques, a considerable portion develop tumor recurrence, which in many cases cannot be detected early, making it the most important factor limiting the long-term survival of HCC patients (67). Thus, it is of utmost importance to find sensitive markers for monitoring postoperative recurrence of HCC and to give adequate treatment for HCC patients (68). A number of 


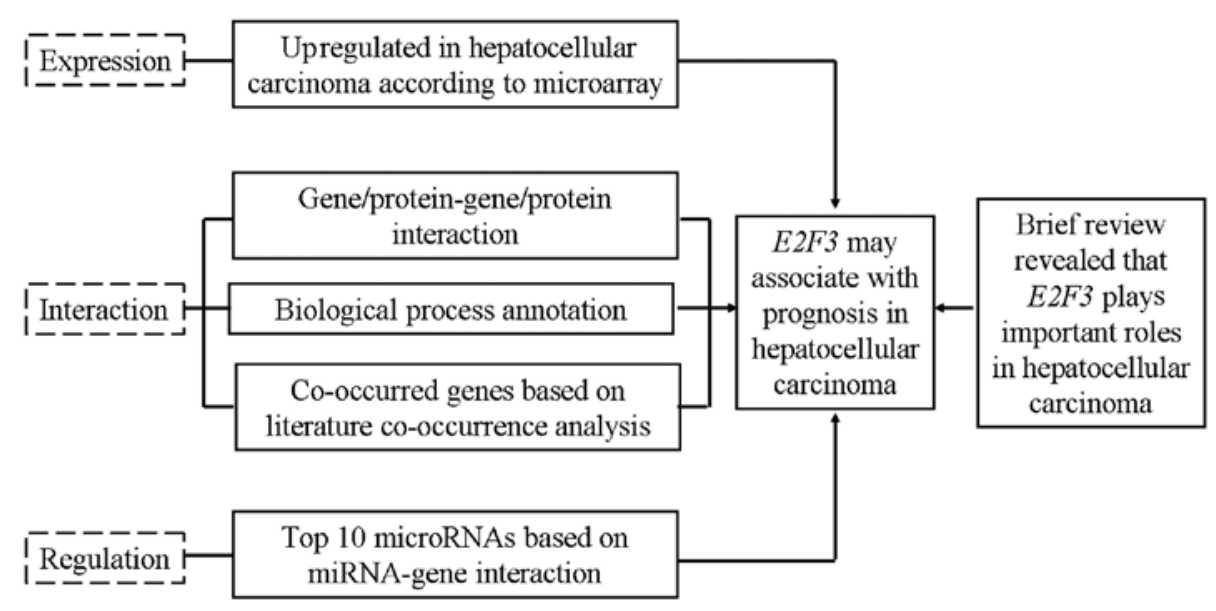

Figure 5. The overall procedure of bioinformatics analysis of E2F3 associated with prognosis in hepatocellular carcinoma. E2F3, E2F transcription factor 3.

factors and parameters would be used as biomarkers for prognosis in patients with HCC; for example, Hao et al (5) revealed that 6 common clinicopathologic parameters including tumor size, number of tumor nodules, tumor stage, venous infiltration status and serum $\alpha$-fetoprotein and total albumin levels are significantly associated with the overall HCC survival and disease-free survival. However, most studies focus on circulating proteins, DNA, microRNAs (miRNAs), cancer cells and regulatory $\mathrm{T}$ cells as serological prognostic biomarkers for patients with HCC (66) and, among these, the dys-expression of certain genes as promising prognosis markers for patients with HCC.

Gene function prediction based on bioinformatics analysis is a potential, feasible and valuable way for gene function mining and many large-scale networks of molecular interactions within the cell have made it possible to go beyond one dimensional approaches to study protein function in the context of a network (69). ONCOMINE is a cancer microarray database and web-based data-mining platform aimed at facilitating discovery from genome-wide expression analyses. Differential expression analyses comparing most major types of cancer with respective normal tissues as well as a variety of cancer subtypes and clinical-based and pathology-based analyses are available for exploration. Data can be queried and visualized for a selected gene across all analyses or for multiple genes in a selected analysis (16). ONCOMINE contains 65 gene expression datasets comprising nearly 48 million gene expression measurements from over 4,700 microarray experiments by 2004 and the number of array data and genes grew quickly every year. GeneMANIA is a web-based database and tool for prediction of gene function on the basis of multiple networks derived from different genomic or proteomic data/sources. It is fast enough to predict gene function with great accuracy (17). Coremine Medical is a product of the PubGene Company which grew out of Pubgene online tool. Pubgene is a gene/protein database and web-based tool for literature mining. It carries out automated extraction of experimental and theoretical biomedical knowledge from publicly available gene and text databases to create a gene-to-gene co-citation network for millions of named human genes by automated analysis of titles and abstracts in over 10 million MEDLINE records (70). Thus, the associations of E2F3 with prognosis for patients with HCC through these online databases/tools are potentially reliable.

miRNAs are a class of small (22 bp) endogenous noncoding RNAs which regulate gene expression mainly by binding to the 3'-UTR of the target mRNA and leading to mRNA cleavage, destabilization or translational repression (71,72). miRNA-mediated post-transcriptional gene regulation is considered a significant regulator of many cellular processes, both physiological and pathological $(73,74)$. Since miRNAs perform their functions through the regulation on their target genes, it has been well established that miRNAs represent a class of genes with a great potential for use in diagnostics, prognosis and therapy (75); therefore, we can predict the gene function through the functions of miRNAs targeting the gene. In the present study, miRWalk, which covered 9 miRNAmRNA interaction tools, was used to predict the miRNAs which targeted the E2F3. MiRWalk is a comprehensive database on miRNAs, which collects predicted and validated miRNA binding sites on all mRNAs, mitochondrial genes and $10 \mathrm{~kb}$ upstream flanking regions of all known genes of human, mouse and rat. More importantly, the miRWalk is a potential real-time database, in which the 'predicted target module' is updated every 6 months and 'validated target module' is updated every month (18).

Collectively, on the basis of comprehensive bioinformatics analyses including microarray data interpretation, protein-protein interaction, biological processes annotation, gene co-occurrence and miRNA-mRNA interaction (Fig. 5), we demonstrated that E2F3 interacted with tens of genes/ proteins associated with poor prognosis for patients with HCC and other types of cancer (Fig. 2) and gene co-occurrence indicated that E2F3 co-occurred with 14 genes which were all associated with unfavorable prognosis in HCC and other types of cancer (Fig. 3). Further analysis based on annotation of biological processes suggested that E2F3 is closely related to 12 biological processes which were closely associated with HCC and prognosis. In addition, the top 10 miRNAs targeted to the E2F3 are all associated with poor prognosis for patients with cancer (Table I). These results indicated that E2F3, which interacted with a large number of genes, proteins, miRNAs and biological processes which were all associated with poor prognosis, may also be associated with prognosis in HCC and 
other types of cancer. Together with the notable upregulation of E2F3 in HCC (Fig. 1), we illustrated, for the first time, that the overexpression of E2F3 in $\mathrm{HCC}$ may be associated with poor prognosis and it may be an unfavorable biomarker for prognosis in HCC patients. The present study provides important information for further investigation of the prognosis-related functions of E2F3 in HCC.

\section{Acknowledgements}

The research was supported by the National Natural Science Foundation of China (grant no. 81360448).

\section{References}

1. Ferlay J, Shin HR, Bray F, Forman D, Mathers C and Parkin DM: Estimates of worldwide burden of cancer in 2008: GLOBOCAN 2008. Int J Cancer 127: 2893-2917, 2010.

2. Singhal A, Jayaraman M, Dhanasekaran DN and Kohli V: Molecular and serum markers in hepatocellular carcinoma: predictive tools for prognosis and recurrence. Crit Rev Oncol Hematol 82: 116-140, 2012.

3. Midorikawa Y, Makuuchi M, Tang W and Aburatani H: Microarray-based analysis for hepatocellular carcinoma: from gene expression profiling to new challenges. World J Gastroenterol 13: 1487-1492, 2007.

4. Chiriva-Internati M, Grizzi F, Wachtel MS, Jenkins M, Ferrari R, Cobos E and Frezza EE: Biological treatment for liver tumor and new potential biomarkers. Dig Dis Sci 53: 836-843, 2008.

5. Hao K, Luk JM, Lee NP, Mao M, Zhang C, Ferguson MD, Lamb J, Dai H, Ng IO, Sham PC and Poon RT: Predicting prognosis in hepatocellular carcinoma after curative surgery with common clinicopathologic parameters. BMC Cancer 9: 389, 2009.

6. Chao Y, Shih YL, Chiu JH, Chau GY, Lui WY, Yang WK, Lee SD and Huang TS: Overexpression of cyclin A but not Skp 2 correlates with the tumor relapse of human hepatocellular carcinoma. Cancer Res 58: 985-990, 1998.

7. Ohashi R, Gao C, Miyazaki M, Hamazaki K, Tsuji T, Inoue Y, Uemura T, Hirai R, Shimizu N and Namba M: Enhanced expression of cyclin E and cyclin A in human hepatocellular carcinomas. Anticancer Res 21: 657-662, 2001.

8. Attwooll C, Lazzerini Denchi E and Helin K: The E2F family: specific functions and overlapping interests. EMBO J 23: 4709-4716, 2004.

9. Leone G, DeGregori J, Yan Z, Jakoi L, Ishida S, Williams RS and Nevins JR: E2F3 activity is regulated during the cell cycle and is required for the induction of S phase. Genes Dev 12: 2120-2130, 1998.

10. Lees JA, Saito M, Vidal M, Valentine M, Look T, Harlow E, Dyson $\mathrm{N}$ and Helin K: The retinoblastoma protein binds to a family of E2F transcription factors. Mol Cell Biol 13: 7813-7825, 1993.

11. Humbert PO, Verona R, Trimarchi JM, Rogers C, Dandapani S and Lees JA: $E 2 f 3$ is critical for normal cellular proliferation. Genes Dev 14: 690-703, 2000.

12. Vuaroqueaux V, Urban P, Labuhn M, Delorenzi M, Wirapati P, Benz CC, Flury R, Dieterich H, Spyratos F, Eppenberger U and Eppenberger-Castori S: Low E2F1 transcript levels are a strong determinant of favorable breast cancer outcome. Breast Cancer Res 9: R33, 2007.

13. Justenhoven C, Pierl CB, Haas S, Fischer HP, Hamann U, Baisch C, Harth V, Spickenheuer A, Rabstein S, Vollmert C, Illig T, Pesch B, Brüning T, Dippon J, Ko YD and Brauch H: Polymorphic loci of E2F2, CCND1 and CCND3 are associated with HER2 status of breast tumors. Int J Cancer 124: 2077-2081, 2009.

14. Feo F, De Miglio MR, Simile MM, Muroni MR, Calvisi DF, Frau M and Pascale RM: Hepatocellular carcinoma as a complex polygenic disease. Interpretive analysis of recent developments on genetic predisposition. Biochim Biophys Acta 1765: 126-147, 2006.

15. Ogata H, Goto S, Sato K, Fujibuchi W, Bono H and Kanehisa M: KEGG: Kyoto Encyclopedia of Genes and Genomes. Nucleic Acids Res 27: 29-34, 1999.

16. Rhodes DR, Yu J, Shanker K, Deshpande N, Varambally R, Ghosh D, Barrette T, Pandey A and Chinnaiyan AM: ONCOMINE: a cancer microarray database and integrated datamining platform. Neoplasia 6: 1-6, 2004.
17. Mostafavi S, Ray D, Warde-Farley D, Grouios C and Morris Q: GeneMANIA: a real-time multiple association network integration algorithm for predicting gene function. Genome Biol 9 (Suppl 1): S4, 2008.

18. Dweep H, Sticht C, Pandey P and Gretz N: miRWalk - database: prediction of possible miRNA binding sites by 'walking' the genes of three genomes. J Biomed Inform 44: 839-847, 2011.

19. de Leeuw N, Dijkhuizen T, Hehir-Kwa JY, Carter NP, Feuk L, Firth HV, Kuhn RM, Ledbetter DH, Martin CL, van Ravenswaaij-Arts CM, Scherer SW, Shams S, Van Vooren S, Sijmons R, Swertz M and Hastings R: Diagnostic interpretation of array data using public databases and internet sources. Hum Mutat 33: 930-940, 2012.

20. Miles WO, Tschöp K, Herr A, Ji JY and Dyson NJ: Pumilio facilitates miRNA regulation of the E2F3 oncogene. Genes Dev 26: 356-368, 2012.

21. Martinez LA, Goluszko E, Chen HZ, Leone G, Post S, Lozano G, Chen $\mathrm{Z}$ and Chauchereau A: E2F3 is a mediator of DNA damageinduced apoptosis. Mol Cell Biol 30: 524-536, 2010.

22. Olsson AY, Feber A, Edwards S, Te Poele R, Giddings I, Merson S and Cooper CS: Role of E2F3 expression in modulating cellular proliferation rate in human bladder and prostate cancer cells. Oncogene 26: 1028-1037, 2007.

23. Feng B, Wang R, Song HZ and Chen LB: MicroRNA-200b reverses chemoresistance of docetaxel-resistant human lung adenocarcinoma cells by targeting E2F3. Cancer 118: 3365-3376, 2012.

24. Xu T, Zhu Y, Xiong Y, Ge YY, Yun JP and Zhuang SM: MicroRNA-195 suppresses tumorigenicity and regulates $\mathrm{G}_{1} / \mathrm{S}$ transition of human hepatocellular carcinoma cells. Hepatology 50: 113-121, 2009.

25. Tryndyak VP, Ross SA, Beland FA and Pogribny IP: Downregulation of the microRNAs $m i R-34 a, m i R-127$, and $m i R-200 b$ in rat liver during hepatocarcinogenesis induced by a methyldeficient diet. Mol Carcinog 48: 479-487, 2009.

26. Foster CS, Falconer A, Dodson AR, Norman AR, Dennis N, Fletcher A, Southgate C, Dowe A, Dearnaley D, Jhavar S, Eeles R, Feber A and Cooper CS: Transcription factor E2F3 overexpressed in prostate cancer independently predicts clinical outcome. Oncogene 23: 5871-5879, 2004.

27. Wei LX, Zhou RS, Xu HF, Wang JY and Yuan MH: High expression of FOXC1 is associated with poor clinical outcome in non-small cell lung cancer patients. Tumour Biol 34: 941-946, 2013.

28. Wang L, Gu F, Liu CY, Wang RJ, Li J and Xu JY: High level of FOXC1 expression is associated with poor prognosis in pancreatic ductal adenocarcinoma. Tumour Biol 34: 853-858, 2013.

29. Ray PS, Bagaria SP, Wang J, Shamonki JM, Ye X, Sim MS, Steen S, Qu Y, Cui X and Giuliano AE: Basal-like breast cancer defined by FOXC1 expression offers superior prognostic value: a retrospective immunohistochemical study. Ann Surg Oncol 18: 3839-3847, 2011.

30. Xia L, Huang W, Tian D, Zhu H, Qi X, Chen Z, Zhang Y, Hu H, Fan D, Nie Y and Wu K: Overexpression of forkhead box C1 promotes tumor metastasis and indicates poor prognosis in hepatocellular carcinoma. Hepatology 57: 610-624, 2013.

31. Wang L, Wang X, Jie P, Lu H, Zhang S, Lin X, Lam EK, Cui Y, $\mathrm{Yu} \mathrm{J}$ and Jin H: Klotho is silenced through promoter hypermethylation in gastric cancer. Am J Cancer Res 1: 111-119, 2011

32. Jeschke J, Van Neste L, Glöckner SC, Dhir M, Calmon MF, Deregowski V, Van Criekinge W, Vlassenbroeck I, Koch A, Chan TA, Cope L, Hooker CM, Schuebel KE, Gabrielson E, Winterpacht A, Baylin SB, Herman JG and Ahuja N: Biomarkers for detection and prognosis of breast cancer identified by a functional hypermethylome screen. Epigenetics 7: 701-709, 2012.

33. Xie B,Zhou J, Yuan L, Ren F, Liu DC, Li Q and Shu G: Epigenetic silencing of Klotho expression correlates with poor prognosis of human hepatocellular carcinoma. Hum Pathol 44: 795-801, 2013.

34. Wang Q, Wang L, Li D, Deng J, Zhao Z, He S, Zhang Y and Tu Y: Kinesin family member 14 is a candidate prognostic marker for outcome of glioma patients. Cancer Epidemiol 37: 79-84, 2013.

35. Kim TM, Yim SH, Shin SH, Xu HD, Jung YC, Park CK, Choi JY, Park WS, Kwon MS, Fiegler H, Carter NP, Rhyu MG and Chung YJ: Clinical implication of recurrent copy number alterations in hepatocellular carcinoma and putative oncogenes in recurrent gains on 1q. Int J Cancer 123: 2808-2815, 2008.

36. Xu N, Jia D, Chen W, Wang H, Liu F, Ge H, Zhu X, Song Y, Zhang X, Zhang D, Ge D and Bai C: FoxM1 is associated with poor prognosis of non-small cell lung cancer patients through promoting tumor metastasis. PLoS One 8: e59412, 2013. 
37. Wang Y, Wen L, Zhao SH, Ai ZH, Guo JZ and Liu WC: FoxM1 expression is significantly associated with cisplatin-based chemotherapy resistance and poor prognosis in advanced non-small cell lung cancer patients. Lung Cancer 79: 173-179, 2013.

38. Xia L, Mo P, Huang W, Zhang L, Wang Y, Zhu H, Tian D, Liu J, Chen Z, Zhang Y, Hu H, Fan D, Nie Y and Wu K: The TNF- $\alpha /$ ROS/HIF-1-induced upregulation of FoxMI expression promotes HCC proliferation and resistance to apoptosis. Carcinogenesis 33: 2250-2259, 2012.

39. Sun HC, Li M, Lu JL, Yan DW, Zhou CZ, Fan JW, Qin XB, Tang HM and Peng ZH: Overexpression of Forkhead box M1 protein associates with aggressive tumor features and poor prognosis of hepatocellular carcinoma. Oncol Rep 25: 1533-1539, 2011.

40. Agnelli L, Forcato M, Ferrari F, Tuana G, Todoerti K, Walker BA, Morgan GJ, Lombardi L, Bicciato S and Neri A: The reconstruction of transcriptional networks reveals critical genes with implications for clinical outcome of multiple myeloma. Clin Cancer Res 17: 7402-7412, 2011.

41. de Reyniès A, Assié G, Rickman DS, Tissier F, Groussin L, René-Corail F, Dousset B, Bertagna X, Clauser E and Bertherat J: Gene expression profiling reveals a new classification of adrenocortical tumors and identifies molecular predictors of malignancy and survival. J Clin Oncol 27: 1108-1115, 2009.

42. Liu B, Zhang J, Huang C and Liu H: Dyskerin overexpression in human hepatocellular carcinoma is associated with advanced clinical stage and poor patient prognosis. PLoS One 7: e43147, 2012.

43. Liu L, Zhang CZ,Cai M,Fu J, Chen GG and Yun J: Downregulation of polo-like kinase 4 in hepatocellular carcinoma associates with poor prognosis. PLoS One 7: e41293, 2012.

44. Mendler JH, Maharry K, Radmacher MD, Mrózek K, Becker H, Metzeler KH, Schwind S, Whitman SP, Khalife J, Kohlschmidt J, Nicolet D, Powell BL, Carter TH, Wetzler M, Moore JO, Kolitz JE, Baer MR, Carroll AJ, Larson RA, Caligiuri MA, Marcucci G and Bloomfield CD: RUNX1 mutations are associated with poor outcome in younger and older patients with cytogenetically normal acute myeloid leukemia and with distinct gene and microRNA expression signatures. J Clin Oncol 30: 3109-3118, 2012

45. Buechler S: Low expression of a few genes indicates good prognosis in estrogen receptor positive breast cancer. BMC Cancer 9: 243, 2009.

46. Mamat S, Ikeda J, Tian T, Wang Y, Luo W, Aozasa K and Morii E: Transcriptional regulation of aldehyde dehydrogenase 1A1 gene by alternative spliced forms of nuclear factor $\mathrm{Y}$ in tumorigenic population of endometrial adenocarcinoma. Genes Cancer 2: 979-984, 2011.

47. Kong LM, Liao CG, Chen L, Yang HS, Zhang SH, Zhang Z, Bian HJ, Xing JL and Chen ZN: Promoter hypomethylation up-regulates CD147 expression through increasing Sp1 binding and associates with poor prognosis in human hepatocellular carcinoma. J Cell Mol Med 15: 1415-1428, 2011.

48. Zhang W, Zhou L, Ding SM, Xie HY, Xu X, Wu J, Chen QX, Zhang F, Wei BJ, Eldin AT and Zheng SS: Aberrant methylation of the CADM1 promoter is associated with poor prognosis in hepatocellular carcinoma treated with liver transplantation. Oncol Rep 25: 1053-1062, 2011.

49. Song MA, Tiirikainen M, Kwee S, Okimoto G, Yu H and Wong LL: Elucidating the landscape of aberrant DNA methylation in hepatocellular carcinoma. PLoS One 8: e55761, 2013.

50. Zhang YJ, Chen SY, Chen CJ and Santella RM: Polymorphisms in cyclin D1 gene and hepatocellular carcinoma. Mol Carcinog 33: $125-129,2002$

51. Villanueva A and Hoshida Y: Depicting the role of $T P_{53}$ in hepatocellular carcinoma progression. J Hepatol 55: 724-725, 2011.

52. Stroescu C, Dragnea A, Ivanov B, Pechianu C, Herlea V, Sgarbura O, Popescu A and Popescu I: Expression of p53, Bcl-2, VEGF, Ki67 and PCNA and prognostic significance in hepatocellular carcinoma. J Gastrointestin Liver Dis 17: 411-417, 2008.

53. Laurent-Puig P and Zucman-Rossi J: Genetics of hepatocellular tumors. Oncogene 25: 3778-3786, 2006.

54. Frau M, Tomasi ML, Simile MM, Demartis MI, Salis F, Latte G, Calvisi DF, Seddaiu MA, Daino L, Feo CF, Brozzetti S, Solinas G, Yamashita S, Ushijima T, Feo F and Pascale RM: Role of transcriptional and posttranscriptional regulation of methionine adenosyltransferases in liver cancer progression. Hepatology 56: $165-175,2012$.

55. Huang YH, Lin KH, Chen HC, Chang ML, Hsu CW, Lai MW, Chen TC, Lee WC, Tseng YH and Yeh CT: Identification of postoperative prognostic microRNA predictors in hepatocellular carcinoma. PLoS One 7: e37188, 2012.
56. Cheng H, Zhang L, Cogdell DE, Zheng H, Schetter AJ, Nykter M, Harris CC, Chen K, Hamilton SR and Zhang W: Circulating plasma MiR-141 is a novel biomarker for metastatic colon cancer and predicts poor prognosis. PLoS One 6: e17745, 2011.

57. Liu XG, Zhu WY, Huang YY, Ma LN, Zhou SQ, Wang YK, Zeng F, Zhou JH and Zhang YK: High expression of serum miR-21 and tumor miR-200c associated with poor prognosis in patients with lung cancer. Med Oncol 29: 618-626, 2012.

58. Chen HY, Lin YM, Chung HC, Lang YD, Lin CJ, Huang J, Wang WC, Lin FM, Chen Z, Huang HD, Shyy JY, Liang JT and Chen RH: miR-103/107 promote metastasis of colorectal cancer by targeting the metastasis suppressors DAPK and KLF4. Cancer Res 72: 3631-3641, 2012.

59. Brenner B, Hoshen MB, Purim O, David MB, Ashkenazi K, Marshak G, Kundel Y, Brenner R, Morgenstern S, Halpern M, Rosenfeld N, Chajut A, Niv Y and Kushnir M: MicroRNAs as a potential prognostic factor in gastric cancer. World J Gastroenterol 17: 3976-3985, 2011

60. Jamieson NB, Morran DC, Morton JP, Ali A, Dickson EJ, Carter CR, Sansom OJ, Evans TR, McKay CJ and Oien KA: MicroRNA molecular profiles associated with diagnosis, clinicopathologic criteria, and overall survival in patients with resectable pancreatic ductal adenocarcinoma. Clin Cancer Res 18: 534-545, 2012.

61. Hu X, Macdonald DM, Huettner PC, Feng Z, El Naqa IM, Schwarz JK, Mutch DG, Grigsby PW, Powell SN and Wang X: A miR-200 microRNA cluster as prognostic marker in advanced ovarian cancer. Gynecol Oncol 114: 457-464, 2009.

62. Hiroki E, Akahira J, Suzuki F, Nagase S, Ito K, Suzuki T, Sasano H and Yaegashi N: Changes in microRNA expression levels correlate with clinicopathological features and prognoses in endometrial serous adenocarcinomas. Cancer Sci 101: 241-249, 2010.

63. Wang X, Wang J, Ma H, Zhang J and Zhou X: Downregulation of miR-195 correlates with lymph node metastasis and poor prognosis in colorectal cancer. Med Oncol 29: 919-927, 2012.

64. Karakatsanis A, Papaconstantinou I, Gazouli M,Lyberopoulou A, Polymeneas G and Voros D: Expression of microRNAs, miR-21, miR-31, miR-122, miR-145, miR-146a, miR-200c, miR-221, miR-222, and miR-223 in patients with hepatocellular carcinoma or intrahepatic cholangiocarcinoma and its prognostic significance. Mol Carcinog 52: 297-303, 2013.

65. Yu J, Ohuchida K, Mizumoto K, Sato N, Kayashima T, Fujita H, Nakata K and Tanaka M: MicroRNA, hsa-miR-200c, is an independent prognostic factor in pancreatic cancer and its upregulation inhibits pancreatic cancer invasion but increases cell proliferation. Mol Cancer 9: 169, 2010.

66. Wong KF, Xu Z, Chen J, Lee NP and Luk JM: Circulating markers for prognosis of hepatocellular carcinoma. Expert Opin Med Diagn 7: 319-329, 2013.

67. Anzola M: Hepatocellular carcinoma: role of hepatitis B and hepatitis $\mathrm{C}$ viruses proteins in hepatocarcinogenesis. J Viral Hepat 11: 383-393, 2004.

68. Yao DF, Dong ZZ and Yao M: Specific molecular markers in hepatocellular carcinoma. Hepatobiliary Pancreat Dis Int 6 241-247, 2007.

69. Sharan R, Ulitsky I and Shamir R: Network-based prediction of protein function. Mol Syst Biol 3: 88, 2007.

70. Jenssen TK, Laegreid A, Komorowski J and Hovig E: A literature network of human genes for high-throughput analysis of gene expression. Nat Genet 28: 21-28, 2001.

71. Behm-Ansmant I, Rehwinkel J and Izaurralde E: MicroRNAs silence gene expression by repressing protein expression and/or by promoting mRNÁ decay. Cold Spring Harb Symp Quant Biol 71: 523-530, 2006.

72. Bartel DP: MicroRNAs: genomics, biogenesis, mechanism, and function. Cell 116: 281-297, 2004.

73. Kloosterman WP and Plasterk RH: The diverse functions of microRNAs in animal development and disease. Dev Cell 11: 441-450, 2006

74. Croce CM and Calin GA: miRNAs, cancer, and stem cell division. Cell 122: 6-7, 2005.

75. Tili E, Michaille JJ, Gandhi V, Plunkett W, Sampath D and Calin GA: miRNAs and their potential for use against cancer and other diseases. Future Oncol 3: 521-537, 2007. 